\title{
A comparative study of the prevalence of and factors associated with insecticide-treated nets usage among children under 5 years of age
} in households that already own nets in Malawi

Owen Nkoka, Martha Sinya Chipeta, Ying-Chih Chuang, Deleon Fergus and Kun-Yang Chuang*

\begin{abstract}
Background: Despite malaria control programmes having successfully increased the number of households owning insecticide-treated nets (ITNs) in Malawi, the population of people with ITN access but still not using them fluctuated from 13\% in 2010, 5\% in 2012 and then 12\% in 2015. This study aimed to compare the rate and factors associated with ITN usage among children under 5 years of age, living in household with at least one ITN, in Malawi between 2010 and 2015.

Methods: The 2010 and 2015-2016 Malawi Demographic and Health Surveys (MDHSs) were utilized. Only children from households that owned at least one ITN were selected. Multivariate logistic regression analyses were performed to examine associations of child, maternal and household factors with ITN usage.

Results: In total, 12,378 and 10,196 children under 5 years of age were examined from 2010 and 2015-2016, respectively. ITN usage increased from 57.8\% (95\% Confidence interval (Cl): 56.1\%-59.4\%) in 2010 to $69.0 \%$ (95\% Cl 67.4\%$70.5 \%$ ) in 2015. The multivariate analysis revealed that, among others, being aged $\geq 24$ months, having mothers with no formal education or with primary education, residing in a female-headed household, and residing in households that had poor household ITN supply were significantly associated with reduced odds of ITN usage.

Conclusions: ITNs are a key vector control intervention in malaria prevention. This study revealed increased ITN usage among children under 5 years old in the 5 -year period, suggesting that considerable improvements have been made. However, continued efforts to increase awareness of the importance of using ITNs in malaria prevention in Malawi are necessary. Findings from this research provide some policy implications, especially for improving household ITN supply, to improve ITN utilization in Malawi.
\end{abstract}

Keywords: Malaria, Insecticide-treated nets, Malawi, Prevention 


\section{Background}

Malaria is one of the leading causes of death in subSaharan Africa (SSA) [1]. The disease is caused by the Plasmodium parasite and is transmitted by the female Anopheles mosquito [2]. One of the most important efforts in malaria eradication is the vector control approach which aims at interrupting malaria transmission [1]. Indoor residual spraying with an insecticide to kill mosquitoes, and the use of insecticide-treated nets (ITNs) to prevent mosquito bites are recommended for most of SSA countries. In particular, ITNs are a costeffective intervention [3-6], and evidence suggests that they are responsible for a $50 \%$ reduction in the malaria incidence in malaria-endemic countries [6]. Despite increased efforts to improve ITN accessibility, approximately 437,000 children still die from malaria in Africa every year [7]. The World Health Organization states that the African region is the hardest hit by malaria. For instance, 92 and $90 \%$ of all malaria cases and deaths in 2016 worldwide occurred in this region [1]. Additionally, most of these deaths occurred in children under the age of 5 years [1].

Malaria is endemic in Malawi, and there is a huge burden of the disease among children under 5 years old [8]. Malawi experiences perennial malaria transmission with peaks observed in the rainy season between November and April [9]. In 2009, 34\% of all outpatient visits, and $40 \%$ of all hospitalizations for children under 5 years of age were due to malaria $[10,11]$. In an attempt to control malaria transmission, in 2001, Malawi was the first country in SSA region to initiate a nationwide ITN social marketing programme [11]. The programme successfully increased ITN ownership and access from $27 \%$ and $19 \%$ for ownership and access in 2004 to $57 \%$ and $38 \%$ for ownership and access in 2010, respectively [12]. According to the Roll Back Malaria Monitoring and Evaluation Reference Group, ITN access refers to the proportion of the household population that could have slept under an ITN, assuming each ITN is used by two people and ITN ownership is defined as the proportion of households with at least one ITN [13]. Yet despite the increase in ITN ownership and access, the malaria incidence did not significantly decrease among children [10]. The slow decline in malaria incidence might be attributed to low usage of ITNs among those owning ITNs [12]. Further, a nationwide ITN distribution campaign was conducted in 2012 which increased household ownership of at least one ITN from $58 \%$ in 2010 to $70 \%$ in 2014 [14]. Subsequent to the 2012 nationwide campaign, there are limited nationally representative studies that have examined ITN usage among children under 5 years in Malawi.

This study examined factors associated with ITN usage among children under 5 years who live in households that already own an ITN in Malawi between 2010 and 2015-2016. Specifically, using nationally representative samples, the study compared ITN usage, and associated factors before and after the nationwide ITN distribution campaign conducted in 2012.

\section{Methods}

This was a cross-sectional study that utilized data from the 2010 and 2015-2016 Malawi Demographic and Health Surveys (MDHSs). Datasets used for this study, and their documentation can be downloaded, upon request, from https://dhsprogram.com/data/availabledatasets.cfm. Briefly, both the 2010 and 2015-2016 MDHSs used the 2008 Malawi Population and Housing Census (MPHC) as the sampling frame [12, 15]. The surveys used a stratified, two-stage, cluster sampling method to select nationally representative samples. The first stage involved selection of enumeration areas (EAs), as defined by the MPHC. The second stage involved selection of households in each EA using probability systematic selection. In 2010, totals of 20 and 35 households from rural and urban clusters were selected, respectively, while 30 and 33 households from urban and rural clusters, respectively, were selected in 2015.

Data were collected through face-to-face interviews from June to November 2010 for the 2010 survey and from October 2015 to February 2016 for the 2015-2016 survey [12, 15]. The survey questionnaires collected information on the mother's demographics, children's illnesses, ITN use, etc. from women aged 15-49 years [13]. The current analysis was restricted to children under 5 years old from households that owned at least one ITN. In this study, data from both the household and mother questionnaires were used.

\section{Variables}

\section{Outcome variable}

The outcome variable was ITN usage defined as whether a child under 5 years of age, living in a household that owned at least one ITN, had slept in an ITN the previous night before the survey. This was assessed as a categorical variable (yes/no).

\section{Independent variables}

Three sets of independent variables were considered in the analysis, namely child factors, maternal characteristics and household factors. Child factors included age in months $(\leq 12,13-23, \geq 24)$, and gender of the child (male and female). Maternal characteristics included age in years $(15-24,25-34, \geq 35)$, educational level (no formal education, primary, secondary/postsecondary), employed (yes, no), ethnicity (Chewa, Tumbuka, Lomwe, Yao, Ngoni, others), marital status 
(married, unmarried), religion (Catholic, Protestant, Muslim, others), women's health behaviours (undesirable vs desirable). Women's health behaviour was measured using two constructs; number of antenatal care visits $(<4$ vs $\geq 4)$ [16] and baby postnatal check within 2 months (no vs yes). The composite score from the two dimensions ranged from 0 to 2, with 0 (none of the two services) and 1 (one of the two services) representing undesirable health behaviour, and 2 (those who confirmed to have used the two services) representing desirable health behaviours. Finally, household factors included the gender of the head of the household (male, female), roofing materials (improved: cement and roofing shingles; unimproved: no roof, thatch/palm leaf, sod, rudimentary, rustic mat, palm/ bamboo, wood planks, cardboard, wood, others) [17], region (northern, central, southern), and residence (urban, rural). A principal component analysis (PCA) model was used to measure household wealth from a set of materials owned by a household such as bicycles, televisions, etc. Scores were then grouped into quintiles with the upper $20 \%$ categorized as richest, the next $20 \%$ as richer, middle $20 \%$ as middle, penultimate $20 \%$ as poorer, and lower $20 \%$ as poorest. Household ITN supply was defined as ITN: member ratio within the household [13]. This variable was categorized as very poor (where more than 3 household members had access to 1 ITN), poor (where exactly 3 household members had access to 1 ITN) and good (where exactly 2 household members had access to 1 ITN or where the household had more ITNs than the number of household members).

\section{Statistical analysis}

Pooled data from the two survey waves were first analysed to compare differences in the distributions of socio-economic factors between the two surveys using a Chi squared $\left(X^{2}\right)$ test. Thereafter, the survey waves were separately analysed. Further, $\chi^{2}$ tests were used to examine the relationship between socio-economic factors and ITN utilization. Associations of child, maternal, and household characteristics with ITN non-use were examined using a multivariate logistic regression. Results from the multivariate logistic regression were reported as the adjusted odds ratio (aOR) and 95\% confidence interval (CI). The level of statistical significance was set at $5 \%$. All analyses took into consideration the complex sample design of the MDHS by applying the "svy" command. The svy command accounts for sampling weights and clustering effects in the dataset. All analyses were performed using Stata vers. 15.0 (Stata Corp., College Station, TX, USA).

\section{Ethical considerations}

The procedures and questionnaires for the standard demographic health survey (DHS) surveys were reviewed and approved by the International Classification of Functioning Disability and Health Institutional Review Board, and ethical clearance was obtained from the Malawi Health Sciences Research. Informed consent was obtained at the start of each interview. Permission to use of the data was sought from the DHS programme.

\section{Results}

\section{Distribution of participants by survey year}

Totals of 12,378 and 10,196 children under 5 years old were analysed in 2010 and 2015-2016, respectively. Differences between the 2010 and 2015-2016 surveys were significant in terms of the ages of the children, maternal ages, educational levels, employed, marital statuses, health behaviour, gender of the head of the household, and roofing materials (all $p<0.05)$ (Table 1$)$. There were no significant differences between the remaining factors between the two survey years.

\section{Distribution of participants according to ITN usage}

The rate for ITN use was $57.8 \%$ (95\% Confidence interval (CI) $56.1 \%-59.4 \%$ ) in 2010 compared to $69.0 \%$ (95\% CI $67.4 \%-70.5 \%$ ) in 2015 (Table 2). Table 2 further reveals that in both survey years, ITN usage was associated with a child being $\leq 12$ months old, the mother being aged $\leq 24$ years, with secondary or post-secondary education, who was married, with desirable health behaviours, and who came from the richest household, living in a male headed household, in urban residence, and with a good ITN supply $(p<0.05)$. Significant $(p<0.05)$ differences were also observed between ITN users and non-users in terms of ethnicity in both survey waves. However, having employed mother was associated with ITN usage in 2015-2016 only, while belonging to catholic religious group was associated with ITN usage in 2010 but not in 2015-2016.

\section{Factors associated with ITN usage}

The odds of ITN usage in the 2010 MDHS were lower among children aged $\geq 24$ months $(\mathrm{aOR}=0.7,95 \% \mathrm{CI}$ $0.6-0.8)$, those whose mother had no formal education or primary education $(\mathrm{aOR}=0.7,95 \%$ CI $0.6-0.9$ and $\mathrm{aOR}=0.8,95 \%$ CI $0.7-0.9$, respectively), those with unmarried mothers $(\mathrm{aOR}=0.8,95 \%$ CI $0.7-0.9)$, those living female headed households $(\mathrm{aOR}=0.8,95 \% \mathrm{CI}$ $0.7-0.9)$ compared to their respective reference groups (Table 3).

In addition, a higher odds of ITN use was observed in those from Chewa, Ngoni, and other ethnic groups 
Table 1 Description of sample characteristics

\begin{tabular}{|c|c|c|c|}
\hline \multirow[t]{2}{*}{ Variable } & $\begin{array}{l}2010 \\
n=12,378\end{array}$ & $\begin{array}{l}2015-2016 \\
n=10,196 \\
\end{array}$ & \multirow[t]{2}{*}{$\begin{array}{l}\text { Comparison } \\
p \text { value }\end{array}$} \\
\hline & $\%$ & $\%$ & \\
\hline
\end{tabular}

Child factors

Age (months)

$\leq 12$

13-23

24-59

Gender of child

Male

Female

Maternal characteristics

Maternal age (years)

$15-24$

24-34

$\geq 35$

Educational level

No formal education

Primary

Secondary/post-secondary

Employed

No

Yes

Ethnicity

Chewa

Tumbuka

Lomwe

Yao

Ngoni

Others

Marital status

Unmarried

Married

Religion

Catholic

Protestant

Muslim and others

Health behaviour

Desirable

Undesirable

Household factors

Wealth

Poorest

Poorer

Middle

Richer

Richest

Gender of head of household

Male

Female
$3032 \quad(24.5) \quad 2608 \quad(25.6)$

$2409 \quad(19.5) \quad 1762 \quad(17.3)$

$6937 \quad(56.0) \quad 5826 \quad(57.1)$

$6045 \quad(48.2) \quad 5077 \quad(49.8)$

$6333 \quad(51.2) \quad 5119 \quad(50.2)$

0.242

0.002

0.013

$\begin{array}{llll}4180 & \text { (33.8) } & 3700 & (36.3)\end{array}$

$5915 \quad(47.8) \quad 4564 \quad(44.8)$

$2283 \quad(18.4) \quad 1932 \quad(18.9)$

$1987 \quad(16.1) \quad 1192 \quad(11.7)$

$8310 \quad(67.1) \quad 6708 \quad(65.8)$

$2081 \quad(16.8) \quad 2296 \quad(22.5)$

$2985 \quad(24.1) \quad 2969 \quad(29.1)$

$9394 \quad(75.9) \quad 7227 \quad(70.9)$

$4326 \quad(35.0) \quad 3566 \quad(35.0)$

$\begin{array}{llll}1081 & (8.7) \quad 938 & (9.2)\end{array}$

$2014 \quad(16.3) \quad 1855 \quad(18.2)$

$1634 \quad(13.2) \quad 1498 \quad(14.7)$

$1449 \quad(11.7) \quad 1154 \quad(11.3)$

$1874 \quad(15.1) \quad 1186 \quad(11.6)$

$1366 \quad(11.0) \quad 1430 \quad(14.0)$

$11,012 \quad(89.0) \quad 8766 \quad(86.0)$

$2655 \quad(21.4) \quad 1900 \quad(18.6)$

$2581 \quad(20.9) \quad 2279 \quad(22.4)$

$\begin{array}{llll}7142 & (57.7) & 6017 & (59.0)\end{array}$

$7889 \quad(64.0) \quad 4447 \quad(36.0)$

$4489 \quad(43.9) \quad 5749 \quad(56.1)$

0.188

$2303 \quad(52.1) \quad 2118 \quad(47.9)$

$2643 \quad(53.6) \quad 2284 \quad(46.4)$

$2786 \quad(27.3) \quad 2076 \quad(42.7)$

$2337 \quad(55.0) \quad 1912 \quad(45.0)$

$2309 \quad(56.1) \quad 1806 \quad(43.9)$

$<0.001$
Table 1 (continued)

\begin{tabular}{|c|c|c|c|c|c|}
\hline \multirow[t]{2}{*}{ Variable } & \multicolumn{2}{|c|}{$\begin{array}{l}2010 \\
n=12,378\end{array}$} & \multicolumn{2}{|c|}{$\begin{array}{l}2015-2016 \\
n=10,196\end{array}$} & \multirow[t]{2}{*}{$\begin{array}{l}\text { Comparison } \\
p \text { value }\end{array}$} \\
\hline & $n$ & $\%$ & $n$ & $\%$ & \\
\hline Roofing material & & & & & $<0.001$ \\
\hline Unimproved & 8418 & $(68.0)$ & 5967 & $(58.5)$ & \\
\hline Improved & 3960 & $(32.0)$ & 4229 & $(41.5)$ & \\
\hline Region & & & & & 0.981 \\
\hline Northern & 1430 & $(11.6)$ & 1167 & (11.4) & \\
\hline Central & 5251 & $(42.4)$ & 4279 & $(42.0)$ & \\
\hline Southern & 5697 & $(46.0)$ & 4750 & $(46.6)$ & \\
\hline Residence & & & & & 0.830 \\
\hline Urban & 1749 & $(14.1)$ & 1393 & $(13.7)$ & \\
\hline Rural & 10629 & $(85.9)$ & 8803 & $(86.3)$ & \\
\hline Household ITN supply & & & & & 0.089 \\
\hline Very poor & 6007 & $(56.0)$ & 4718 & $(44.0)$ & \\
\hline Poor & 3491 & $(54.4)$ & 2930 & $(45.6)$ & \\
\hline Good & 2880 & $(53.1)$ & 2548 & $(46.9)$ & \\
\hline
\end{tabular}

ITN insecticide-treated net

$(\mathrm{aOR}=1.3,95 \%$ CI $1.1-1.7 ; \mathrm{aOR}=1.4,95 \%$ CI 1.1-1.7; and $\mathrm{aOR}=1.3,95 \% \mathrm{CI} 1.1-1.6$, respectively), whose mothers had desirable health behaviours $(\mathrm{aOR}=1.17$, 95\% CI 1.04-1.31), middle, richer, and richest households $(\mathrm{aOR}=1.2,95 \%$ CI $1.1-1.6, \mathrm{aOR}=1.4,95 \%$ CI $1.1-1.7$ and $\mathrm{aOR}=1.7,95 \% \mathrm{CI} 1.3-2.2$, respectively), from households with unimproved roofing material $(\mathrm{aOR}=1.4,95 \%$ CI 1.1-1.7), from the southern region $(\mathrm{aOR}=1.48,95 \%$ CI 1.16-1.89), and from households with poor and good ITN supply $(\mathrm{aOR}=1.9,95 \% \mathrm{CI} 1.6-2.1$ and $\mathrm{aOR}=2.6$, 95\% CI 2.3-2.9, respectively) compared to their respective reference groups (Table 3 ).

In contrast, in 2015-2016, ethnicity, marital status, wealth, roofing material, region, and health promotion did not exhibit significant associations with ITN usage. In 2015-2016, children whose mothers had desirable health behaviours were more likely to sleep under an ITN $(\mathrm{aOR}=1.2,95 \%$ CI 1.1-1.3) compared to those whose mothers did not have desirable health behaviours. Additionally, in 2015-2016, belonging to the Protestant religious group and residing in rural areas were associated with reduced likelihood of ITN usage $(\mathrm{aOR}=0.8,95 \% \mathrm{CI}$ $0.6-0.9)$ and $(\mathrm{aOR}=0.6,95 \%$ CI $0.5-0.8)$ compared to Catholics and urban dwellers, respectively (Table 3).

\section{Discussion}

This is the first nationally representative study to compare ITN usage in children under 5 years old living in households that owned at least one ITN between 2010 and 2015 following the nationwide ITN distribution campaign in 2012. Despite similar ITN access rates between 
the two surveys (38\% for 2010 and $39 \%$ for 2015 ) [12], the rate of ITN usage in children under 5 years old increased from $57.8 \%$ in 2010 to $69.0 \%$ in 2015 . Moreover, the study revealed that many child, maternal and household factors were significantly associated with ITN usage across the two surveys. Specifically, children whose mothers had desirable health behaviours, from households with a good ITN supply, and living in the southern region had increased odds of using ITNs.

The increase in ITN usage observed in this study could probably be attributed to two reasons; First, the nationwide ITN distribution campaign in 2012, and a partial distribution campaign in early 2015 , which were accompanied by awareness messages on the importance of using malaria interventions such as ITNs. In 2015, a higher proportion (32\%) of the interviewed households reported that they sourced their ITNs from mass campaigns than any other sources [12]. Second, the differences in survey periods (i.e. the 2015 survey was largely conducted during malaria transmission peak period (October-February) while most part of the 2010 survey was conducted outside the transmission peak period (June-November). Despite the observed increase in ITN usage, the Malawian ITN usage rate remains relatively lower than that in other countries in SSA such as Rwanda (75\%) [18]. The observed difference in ITN usage rates may be as a result of differences in ITN access rates at the time of the study with Rwanda reporting a relatively high ITN access of $64.2 \%$ compared to the $39 \%$ for Malawi [19]. Additionally, the rates of households owning at least one ITN in Malawi have been fluctuating from 57\% in 2010, 70\% in 2014, and 57\% in 2015 with high rates of ownership observed in the years soon after mass ITN campaigns [12]. The results suggest the need for continued efforts in increasing household ITN ownership and access, through strengthened mass ITN distribution campaigns and routine distribution systems to vulnerable groups.

Children whose mothers were married, had desirable health behaviours, those from middle, rich and richest households, and from households with unimproved roofing were more likely to sleep in an ITN in 2010. Unmarried women may lack support from their spouses and may be disadvantaged in having access to resources [20]. Previous research assessing the association between socio-economic status and net usage revealed conflicting results [5, 21-23]. Mothers from rich and middlewealth households may have better access to information and resources that may help them reinforce the decision to have their children sleep under an ITN [24]. Consistent with a previous study in Ethiopia, having improved roofing in a household may foster a false sense of protection from mosquitoes, and hence families may be more likely to forego nets [25]. Women already practicing good health behaviours might be more receptive to other health-promotion practices, such as the use of ITNs [26]. Ethnicity and geographical regions were highly correlated with cultural beliefs and social norms which may influence health behaviours [27]. A higher malaria prevalence was reported in the southern region than the northern part of Malawi [28]; hence, people in the south may feel vulnerable to malaria, thereby making greater efforts to use intervention strategies already in place [28].

The diminishing influence of these aforementioned factors could be related to the mass ITN distribution campaign that was conducted in 2012, which also included a comprehensive awareness campaign. It further appears that the campaign achieved some moderate success in alleviating the influence of socio-economic factors on net usage, as well as in minimizing cultural and regional differences in net usage. This underscores the importance of mass campaigns in reducing disparities in ITN usage behaviour among various segments of the population in Malawi. Future mass campaigns should, therefore, not only emphasize ITN distribution, but also strengthen behavioural change communication messages related to ITN usage.

Additionally, data indicated that older children ( $\geq 24$ months) were less likely to sleep in an ITN compared to those aged $\leq 12$ months. It was shown that as children grow older, their access to ITN is lost to younger siblings [29]. Moreover, younger children, especially those that are breastfeeding, are more likely to share a bed with their parents, thereby increasing their chances of sleeping under an ITN [21]. Hence, there is a need to holistically enhance ITN usage among all age groups of children to achieve the malaria elimination goal in Malawi. Mother's education remained a significant factor, consistent with previous research [30]. A mother's level of education may portray the level of autonomy the mother has on important issues such as health decisions [31]. Autonomous women were associated with improved health behaviours [32,33] which may subsequently affect the behaviour of their children [34].

Children from households headed by a female were associated with reduced odds of ITN usage. Households headed by a female may have limited access to resources [35], such as radios, newspapers and television to expose them to important health messages compared to households headed by a male, which may ultimately play a role in their health behaviours, including ITN usage for their younger ones. In addition, a male's position on ITNs might influence household ITN usage as reported in Liberia [36]. Similarly, rural residents might have poor access to health-related information and other resources $[3,25,37]$, hence this explains the finding that 
Table 2 Comparison of characteristics by insecticide-treated net (ITN) usage across survey waves

\begin{tabular}{|c|c|c|c|c|c|c|}
\hline \multirow[t]{2}{*}{ Variable } & \multicolumn{2}{|l|}{$\begin{array}{l}2010 \\
n=12,378\end{array}$} & \multirow[t]{2}{*}{$p$ value } & \multicolumn{2}{|l|}{$\begin{array}{l}2015-2016 \\
n=10,196\end{array}$} & \multirow[t]{2}{*}{$p$ value ${ }^{a}$} \\
\hline & $\begin{array}{l}n(\%) \\
\text { Yes } \\
n=7151\end{array}$ & $\begin{array}{l}n(\%) \\
\text { No } \\
n=5227\end{array}$ & & $\begin{array}{l}n(\%) \\
\text { Yes } \\
n=7033\end{array}$ & $\begin{array}{l}n(\%) \\
\text { No } \\
n=3163\end{array}$ & \\
\hline \multicolumn{7}{|l|}{ Child factors } \\
\hline Age (months) & & & $<0.001$ & & & $<0.001$ \\
\hline$\leq 12$ & $1914(63.1)$ & $1118(36.9)$ & & $1965(75.3)$ & $643(24.7)$ & \\
\hline $13-23$ & $1463(60.7)$ & $946(39.3)$ & & $1297(73.6)$ & $465(26.4)$ & \\
\hline $24-59$ & $3774(54.4)$ & $3163(45.6)$ & & $3771(64.7)$ & $2055(35.3)$ & \\
\hline Gender of child & & & 0.202 & & & 0.917 \\
\hline Male & $3446(57.0)$ & $2599(43.0)$ & & $3506(69.0)$ & $1571(31.0)$ & \\
\hline Female & $3705(58.5)$ & $2628(41.5)$ & & $3527(68.9)$ & $1592(31.1)$ & \\
\hline \multicolumn{7}{|l|}{ Maternal characteristics } \\
\hline Maternal age (years) & & & 0.012 & & & 0.038 \\
\hline $15-24$ & $2431(58.2)$ & $1749(41.8)$ & & $2617(70.8)$ & $1083(29.2)$ & \\
\hline $24-34$ & $3497(59.1)$ & $2418(40.9)$ & & $3138(68.8)$ & $1426(31.2)$ & \\
\hline$\geq 35$ & $1223(53.6)$ & $1060(46.4)$ & & $1278(66.1)$ & $654(33.9)$ & \\
\hline Educational level & & & $<0.001$ & & & $<0.001$ \\
\hline No formal education & $1009(50.8)$ & $878(49.2)$ & & $712(59.7)$ & $480(40.3)$ & \\
\hline Primary & $4702(56.6)$ & $3608(43.4)$ & & $4552(67.9)$ & $2156(32.1)$ & \\
\hline Secondary/Post-secondary & $1440(69.2)$ & $641(30.8)$ & & $1769(77.0)$ & $527(23.0)$ & \\
\hline Employed & & & 0.131 & & & 0.004 \\
\hline No & $1784(59.8)$ & $1201(40.2)$ & & $2131(71.8)$ & $838(28.2)$ & \\
\hline Yes & $5367(57.1)$ & $4027(42.9)$ & & $4902(67.8)$ & $2325(32.2)$ & \\
\hline Ethnicity & & & 0.019 & & & 0.043 \\
\hline Chewa & $2529(58.4)$ & $1797(41.6)$ & & $2380(66.7)$ & $1186(33.3)$ & \\
\hline Tumbuka & $565(52.2)$ & $516(47.8)$ & & $663(70.7)$ & $275(29.3)$ & \\
\hline Lomwe & $1125(55.9)$ & $889(44.1)$ & & $1307(70.5)$ & $547(29.5)$ & \\
\hline Yao & $904(55.3)$ & $730(44.7)$ & & 1017 (67.9) & $481(32.1)$ & \\
\hline Ngoni & $882(60.9)$ & $567(39.1)$ & & $855(74.1)$ & $299(25.9)$ & \\
\hline Others & $1146(61.1)$ & $728(38.9)$ & & $811(68.3)$ & $375(31.7)$ & \\
\hline Marital status & & & $<0.001$ & & & 0.002 \\
\hline Unmarried & $670(49.1)$ & $696(50.9)$ & & $919(64.3)$ & $511(35.7)$ & \\
\hline Married & $6481(58.9)$ & $4531(41.1)$ & & $6114(69.7)$ & $2652(30.3)$ & \\
\hline Religion & & & 0.001 & & & 0.361 \\
\hline Catholic & $1590(59.9)$ & $1065(40.1)$ & & $1351(71.1)$ & $549(28.9)$ & \\
\hline Protestant & $1587(61.5)$ & 994 (38.5) & & $1567(68.8)$ & $712(31.2)$ & \\
\hline Muslim and others & 3974 (55.6) & $3168(44.4)$ & & $4115(68.4)$ & $1902(31.6)$ & \\
\hline Health behaviour & & & $<0.001$ & & & $<0.001$ \\
\hline Undesirable & $4363(55.3)$ & $3526(44.7)$ & & $2887(64.9)$ & $1560(35.1)$ & \\
\hline Desirable & $2788(62.1)$ & $1701(37.9)$ & & $4146(72.1)$ & $1603(27.9)$ & \\
\hline \multicolumn{7}{|l|}{ Household factors } \\
\hline Wealth & & & $<0.001$ & & & $<0.001$ \\
\hline Poorest & $1159(50.3)$ & $1144(49.7)$ & & $1372(64.8)$ & $746(35.2)$ & \\
\hline Poorer & $1394(52.8)$ & $1249(47.2)$ & & $1531(67.0)$ & $753(33.0)$ & \\
\hline Middle & 1633 (58.6) & $1153(41.4)$ & & $1415(68.2)$ & $661(31.8)$ & \\
\hline Richer & $1392(59.6)$ & $945(40.4)$ & & 1330 (69.6) & $582(30.4)$ & \\
\hline Richest & $1573(68.1)$ & $736(31.9)$ & & $1385(76.7)$ & $421(23.3)$ & \\
\hline Gender of head of household & & & $<0.001$ & & & 0.003 \\
\hline Male & $5997(59.3)$ & $4108(40.7)$ & & $5507(70.0)$ & $2361(30.0)$ & \\
\hline Female & $1154(50.8)$ & $1119(49.2)$ & & $1526(65.6)$ & $802(34.0)$ & \\
\hline
\end{tabular}


Table 2 (continued)

\begin{tabular}{|c|c|c|c|c|c|c|}
\hline \multirow[t]{2}{*}{ Variable } & \multicolumn{2}{|l|}{$\begin{array}{l}2010 \\
n=12,378\end{array}$} & \multirow[t]{2}{*}{$p$ value } & \multicolumn{2}{|l|}{$\begin{array}{l}2015-2016 \\
n=10,196\end{array}$} & \multirow[t]{2}{*}{$p$ value $^{a}$} \\
\hline & $\begin{array}{l}n(\%) \\
\text { Yes } \\
n=7151\end{array}$ & $\begin{array}{l}n(\%) \\
\text { No } \\
n=5227\end{array}$ & & $\begin{array}{l}n(\%) \\
\text { Yes } \\
n=7033\end{array}$ & $\begin{array}{l}n(\%) \\
\text { No } \\
n=3163\end{array}$ & \\
\hline Roofing material & & & $<0.001$ & & & 0.001 \\
\hline Unimproved & $4690(55.7)$ & $3728(44.3)$ & & $3996(67.0)$ & $1971(33.0)$ & \\
\hline Improved & $2461(62.1)$ & 1499 (37.9) & & $3037(71.8)$ & $1192(28.2)$ & \\
\hline Region & & & 0.127 & & & 0.289 \\
\hline Northern & $768(53.7)$ & $662(46.3)$ & & $828(71.0)$ & $339(29.0)$ & \\
\hline Central & $3022(57.6)$ & $2229(42.4)$ & & $2896(67.7)$ & $1383(32.3)$ & \\
\hline Southern & $3361(59.0)$ & $2336(41.0)$ & & $2208(69.7)$ & $1442(30.3)$ & \\
\hline Residence & & & $<0.001$ & & & $<0.001$ \\
\hline Urban & $1197(68.4)$ & $552(31.6)$ & & $1111(79.7)$ & $282(20.3)$ & \\
\hline Rural & $5954(56.0)$ & $4675(44.0)$ & & $5922(67.3)$ & $2881(32.7)$ & \\
\hline Household ITN supply & & & $<0.001$ & & & $<0.001$ \\
\hline Very poor & $2849(47.4)$ & $3158(52.6)$ & & $2696(57.2)$ & $2022(42.8)$ & \\
\hline Poor & $2232(63.9)$ & $1259(36.1)$ & & $2209(75.4)$ & $721(24.6)$ & \\
\hline Good & $2070(71.9)$ & $810(28.1)$ & & $2128(83.5)$ & $420(16.5)$ & \\
\hline
\end{tabular}

a All p values were determined by a Chi-square test

children from rural areas being less likely to use ITN compared to urban residents. Moreover, households in rural areas might also face problems of limited public health resources and administrative support within the community.

ITN usage is largely dependent on access [13]. This study demonstrated increased odds of ITN usage among children from households with good ITN supply compared to those with very poor ITN supply. Compared to smaller households, larger households face challenges in achieving desirable intra-household ITN supply [38]. This finding underscores the need for malaria programmes to take into consideration family sizes during ITN distribution which may help increase intra-household ITN supply and, ultimately, help improve usage.

In 2015, those belonging to the Protestant religious group had reduced odds of using ITN compared to belonging to the Catholic religious group. This is consistent with a previous study in Ghana where Catholics were more likely to use ITNs compared to those who practiced traditionalism [39]. Efforts to enhance ITN utilization should consider partnership with community religious institutions as an essential approach to scaling up ITN utilization by children.

There are several limitations to this study that should be noted. First, because of the limited number of variables in the MDHS, an array of other important factors related to ITN usage, particularly user-side factors, such as satisfaction with the nets or difficulties associated with using the nets, were not examined. However, this study captured many important child, maternal and household characteristics that could prove vital for effective ITN programmes. Second, the cross-sectional design limited the study from drawing causal inferences between explanatory factors and ITN usage. Third, the study used wealth quintiles which were calculated using PCA model and not multiple component analysis which has been shown to provide more accurate wealth index because of its ability to accommodate both continuous and dichotomous variables [40]. The inability of PCA analysis to accommodate continuous variables makes it difficult to determine wealth quintile cut-off points where most households have the same assets which may result in allocating the same or very similar wealth scores [40]. Finally, the question on ITN usage by children was asked from the mother which could be subject to social desirability bias as mothers may want to prove that they are taking good care of their children by making them sleep under ITNs. Despite these limitations, the study provides evidence of the importance of considering child, maternal and household characteristics, in both research and actual practice, to promote the use of ITNs.

\section{Conclusions}

This study examined associations between ITN usage and a comprehensive list of child, maternal and household characteristics. Results demonstrated a considerable increase in the rates of ITN usage among children 
Table 3 Multivariate analyses of factors associated with insecticide-treated net (ITN) usage among children under 5 years old

\begin{tabular}{|c|c|c|c|c|c|c|}
\hline \multirow[t]{2}{*}{ Variable } & \multicolumn{3}{|l|}{2010} & \multicolumn{3}{|c|}{ 2015-2016 } \\
\hline & aOR & $95 \% \mathrm{Cl}$ & $p$ value & $\mathrm{aOR}$ & $95 \% \mathrm{Cl}$ & $p$ value \\
\hline \multicolumn{7}{|l|}{ Child factors } \\
\hline \multicolumn{7}{|l|}{ Age (months) } \\
\hline$\leq 12$ & 1.0 & & & 1.0 & & \\
\hline $13-23$ & 0.9 & $(0.8-1.1)$ & 0.078 & 0.9 & $(0.8-1.1)$ & 0.353 \\
\hline $24-59$ & 0.7 & $(0.6-0.8)$ & $<0.001$ & 0.6 & $(0.5-0.7)$ & $<0.001$ \\
\hline \multicolumn{7}{|l|}{ Gender of child } \\
\hline Male & 1.0 & & & 1.0 & & \\
\hline Female & 1.1 & $(0.9-1.2)$ & 0.050 & 1.0 & $(0.9-1.1)$ & 0.899 \\
\hline \multicolumn{7}{|l|}{ Maternal characteristics } \\
\hline \multicolumn{7}{|l|}{ Maternal age (years) } \\
\hline $15-24$ & 1.0 & & & 1.0 & & \\
\hline $24-34$ & 1.2 & $(1.0-1.3)$ & 0.042 & 1.1 & $(0.9-1.3)$ & 0.349 \\
\hline$\geq 35$ & 1.1 & $(0.9-1.3)$ & 0.214 & 1.1 & $(0.9-1.4)$ & 0.177 \\
\hline \multicolumn{7}{|l|}{ Educational level } \\
\hline Secondary/post-secondary & 1.0 & & & 1.0 & & \\
\hline No formal education & 0.7 & $(0.6-0.9)$ & 0.002 & 0.6 & $(0.49-0.8)$ & 0.001 \\
\hline Primary & 0.8 & $(0.7-0.9)$ & 0.011 & 0.8 & $(0.67-0.9)$ & 0.008 \\
\hline \multicolumn{7}{|l|}{ Employed } \\
\hline No & 1.0 & & & 1.0 & & \\
\hline Yes & 0.9 & $(0.8-1.1)$ & 0.641 & 0.9 & $(0.8-1.0)$ & 0.076 \\
\hline \multicolumn{7}{|l|}{ Ethnicity } \\
\hline Lomwe & 1.0 & & & 1.0 & & \\
\hline Chewa & 1.3 & $(1.1-1.7)$ & 0.019 & 0.9 & $(0.7-1.2)$ & 0.501 \\
\hline Tumbuka & 0.9 & $(0.7-1.3)$ & 0.685 & 0.9 & $(0.7-1.3)$ & 0.622 \\
\hline Yao & 1.1 & $(0.8-1.3)$ & 0.688 & 0.9 & $(0.8-1.3)$ & 0.927 \\
\hline Ngoni & 1.4 & $(1.1-1.7)$ & 0.008 & 1.1 & $(0.9-1.5)$ & 0.265 \\
\hline Others & 1.3 & $(1.1-1.6)$ & 0.002 & 0.8 & $(0.7-1.1)$ & 0.177 \\
\hline \multicolumn{7}{|l|}{ Marital status } \\
\hline Married & 1.0 & & & 1.0 & & \\
\hline Unmarried & 0.8 & $(0.7-0.9)$ & 0.013 & 0.8 & $(0.7-1.0)$ & 0.089 \\
\hline \multicolumn{7}{|l|}{ Religion } \\
\hline Catholic & 1.0 & & & 1.0 & & \\
\hline Protestant & 0.9 & $(0.8-1.2)$ & 0.923 & 0.8 & $(0.6-0.9)$ & 0.043 \\
\hline Muslim and other & 0.9 & $(0.8-1.1)$ & 0.253 & 0.9 & $(0.8-1.1)$ & 0.224 \\
\hline \multicolumn{7}{|l|}{ Health behaviour } \\
\hline Undesirable & 1.0 & & & 1.00 & & \\
\hline Desirable & 1.2 & $(1.1-1.3)$ & 0.001 & 1.2 & $(1.1-1.3)$ & 0.016 \\
\hline \multicolumn{7}{|l|}{ Household factors } \\
\hline \multicolumn{7}{|l|}{ Wealth } \\
\hline Poorest & 1.00 & & & 1.00 & & \\
\hline Poorer & 0.9 & $(0.8-1.2)$ & 0.861 & 1.0 & $(0.8-1.2)$ & 0.970 \\
\hline Middle & 1.2 & $(1.1-1.6)$ & 0.012 & 1.0 & $(0.9-1.3)$ & 0.725 \\
\hline Richer & 1.4 & $(1.1-1.7)$ & 0.004 & 0.9 & $(0.8-1.3)$ & 0.944 \\
\hline Richest & 1.7 & $(1.3-2.2)$ & $<0.001$ & 0.8 & $(0.6-1.2)$ & 0.275 \\
\hline \multicolumn{7}{|l|}{ Gender of head of household } \\
\hline Male & 1.0 & & & 1.0 & & \\
\hline Female & 0.8 & $(0.7-0.9)$ & 0.002 & 0.8 & $(0.7-0.9)$ & 0.012 \\
\hline
\end{tabular}


Table 3 (continued)

\begin{tabular}{|c|c|c|c|c|c|c|}
\hline \multirow[t]{2}{*}{ Variable } & \multicolumn{3}{|l|}{2010} & \multicolumn{3}{|c|}{ 2015-2016 } \\
\hline & aOR & $95 \% \mathrm{Cl}$ & $p$ value & aOR & $95 \% \mathrm{Cl}$ & $p$ value \\
\hline \multicolumn{7}{|l|}{ Roofing material } \\
\hline Improved & 1.0 & & & 1.0 & & \\
\hline Unimproved & 1.4 & $(1.1-1.7)$ & 0.001 & 1.0 & $(0.8-1.2)$ & 0.910 \\
\hline \multicolumn{7}{|l|}{ Region } \\
\hline Northern & 1.0 & & & 1.0 & & \\
\hline Central & 1.2 & $(0.9-1.6)$ & 0.237 & 0.8 & $(0.6-1.1)$ & 0.261 \\
\hline Southern & 1.5 & $(1.2-1.9)$ & 0.002 & 0.9 & $(0.8-1.3)$ & 0.973 \\
\hline \multicolumn{7}{|l|}{ Residence } \\
\hline Urban & 1.0 & & & 1.0 & & \\
\hline Rural & 0.8 & $(0.6-1.1)$ & 0.060 & 0.6 & $(0.5-0.8)$ & 0.001 \\
\hline \multicolumn{7}{|c|}{ Household ITN supply } \\
\hline Very poor & 1.0 & & & 1.0 & & \\
\hline Poor & 1.9 & $(1.6-2.1)$ & $<0.001$ & 2.3 & $(1.9-2.6)$ & $<0.001$ \\
\hline Good & 2.6 & $(2.3-2.9)$ & $<0.001$ & 3.8 & $(3.2-4.5)$ & $<0.001$ \\
\hline
\end{tabular}

aOR adjusted odds ratio, $\mathrm{Cl}$ confidence interval, ITN insecticide treated nets

under 5 years old in Malawi following a nationwide ITN distribution campaign in 2012. However, more should be done to increase ITN usage, and public health practitioners should consider factors identified in this study when distributing and promoting ITN usage in Malawi.

\section{Abbreviations}

ITN: insecticide-treated nets; aOR: adjusted odds ratio; Cl: confidence interval; EA: enumeration area; PCA: principle component analysis; SSA: sub-Saharan Africa; DHS: Demographic Health Survey; MDHSs: Malawi Demographic Health Surveys; ICF: International Classification of Functioning Disability and Health; MPHC: Malawi Population and Housing Census.

\section{Authors' contributions}

MSC and ON are Malawian scientists studying at Taipei Medical University. ON worked on Maternal and Child Health programmes in Malawi, including a malaria programme with World Vision, Malawi, from 2015 to 2016. MSC and KYC developed the study. ON and MSC conducted the data analysis; YCC and KYC supervised the data analysis; and all co-authors contributed to data interpretation. ON and MSC wrote the first draft of the manuscript, and DF assisted in manuscript preparation and literature review. All co-authors contributed to the final version. All authors read and approved the final manuscript.

\section{Acknowledgements}

The authors would like to thank ICF Macro (Measure DHS) for granting access to the data for this study.

\section{Competing interests}

The authors declare that they have no competing interests.

\section{Availability of data and materials}

The study used, with permission, data from the International Classification of Functioning, Disability, and Health (ICF). The data are publicly available and may be requested from the ICF through https://dhsprogram.com/data/avail able-datasets.cfm.

\section{Consent for publication}

Not applicable.

\section{Ethics approval and consent to participate}

The survey protocol was reviewed and approved by the National Health Sciences Research Board of Malawi, the IRB of ICF Macro, and the CDC in Atlanta. Informed consent was obtained at the beginning of each interview, and permission was sought from the DHS programme to analyse the data.

\section{Funding}

None.

\section{Publisher's Note}

Springer Nature remains neutral with regard to jurisdictional claims in published maps and institutional affiliations.

Received: 29 November 2018 Accepted: 27 January 2019

Published online: 20 February 2019

\section{References}

1. WHO. World malaria report 2017. Geneva: World Health Organization; 2017.

2. WHO. Malaria. Geneva: World Health Organization http://www.who.int/ mediacentre/factsheets/fs094/en/. Accessed 21 January 2019.

3. García-Basteiro AL, Schwabe C, Aragon C, Baltazar G, Rehman AM, Matias A, et al. Determinants of bed net use in children under five and household bed net ownership on Bioko Island, Equatorial Guinea. Malar J. 2011;10:179.

4. Korenromp EL, Miller J, Cibulskis RE, Kabir Cham M, Alnwick D, Dye C. Monitoring mosquito net coverage for malaria control in Africa: possession vs. use by children under 5 years. Trop Med Int Health. 2003;8:693-703.

5. Mugisha F, Arinaitwe J. Sleeping arrangements and mosquito net use among under-fives: results from the Uganda Demographic and Health Survey. Malar J. 2003:2:40.

6. Lengeler $C$. Insecticide-treated bed nets and curtains for preventing malaria. Cochrane Database Syst Rev. 2004. https://doi. org/10.1002/14651858.CD000363.pub2. Accessed 21 January 2019.

7. WHO. Fact Sheet on the World Malaria Report 2014. Geneva: World Health Organization. https://www.who.int/malaria/media/world_malar ia_report_2014/en/. Accessed 21 January 2019. 
8. Mathanga DP, Walker ED, Wilson ML, Ali D, Taylor TE, Laufer MK. Malaria control in Malawi: current status and directions for the future. Acta Trop. 2012;121:212-7.

9. Presidential Malaria Initiative. Malawi Country Profile. https://www.pmi. gov/docs/default-source/default-document-library/country-profiles/ malawi_profile.pdf?sfvrsn=24. Accessed 21 January 2019.

10. National Malaria Control Programme - NMCP/Malawi, ICF International: Malawi Malaria Indicator Survey. Lilongwe. Malawi: NMCP/Malawi and ICF International; 2012. p. 2012.

11. Malawi Ministry of Health. Malaria strategic plan 2011-2015 towards universal access. National Malaria Control Programme Community Health Sciences Unit. https://www.medbox.org/malaria-strategicplan-2011-2015/download.pdf. Accessed 21 January 2019.

12. National Statistical Ofce (NSO) [Malawi] and ICF 2017. Malawi demographic and health survey 2015-2016. Zomba: NSO and ICF; 2017. p. 2017.

13. MEASURE Evaluation, MEASURE DHS, President's Malaria Initiative, Roll Back Malaria Partnership, UNICEF, World Health Organization. Household survey indicators for malaria control. 2018.

14. National Malaria Control Programme-NMCP/Malawi, ICF International: Malawi Malaria Indicator Survey 2014. Rockville, Maryland, USA: NMCP/ Malawi and ICF International; 2015.

15. National Statistical Office-NSO/Malawi, ICF Macro: Malawi Demographic and Health Survey 2010. Zomba, Malawi: NSO/Malawi and ICF Macro; 2011.

16. WHO. Recommendations on antenatal care for a positive pregnancy experience. Geneva: World Health Organization; 2016. http://apps.who. int/iris/bitstream/10665/250796/1/9789241549912-eng.pdf. Accessed 21 January 2019.

17. Adebowale SA, Morakinyo OM, Ana GR. Housing materials as predictors of under-five mortality in Nigeria: evidence from 2013 demographic and health survey. BMC Pediatr. 2017;17:30.

18. Ruyange MM, Condo J, Karema C, Binagwaho A, Rukundo A, Muyirukazi Y. Factors associated with the non-use of insecticide-treated nets in Rwandan children. Malar J. 2016;15:355.

19. Koenker H, Ricotta E, Olapeju B. Insecticide-treated nets (ITN) access and use report. Baltimore, MD PMI| VectorWorks Project, Johns Hopkins Center for Communication Programs 2018

20. Levitz NR, Haji-Jama S, Munro T, Gorey KM, Luginaah IN, Bartfay E, et al. Multiplicative disadvantage of being an unmarried and inadequately insured woman living in poverty with colon cancer: historical cohort exploration in California. BMC Womens Health. 2015:15:8.

21. Auta A. Demographic factors associated with insecticide treated net use among Nigerian women and children. North Am J Med Sci. 2012;4:40-4.

22. Woyessa A, Deressa W, Ali A, Lindtjørn B. Ownership and use of long-lasting insecticidal nets for malaria prevention in Butajira area, south-central Ethiopia: complex samples data analysis. BMC Public Health. 2014;14:99.

23. Oresanya OB, Hoshen M, Sofola OT. Utilization of insecticide-treated nets by under-five children in Nigeria: assessing progress towards the Abuja targets. Malar J. 2008;7:145.

24. Ricci F. Social implications of malaria and their relationships with poverty. Mediterr J Hematol Infect Dis. 2012;4:e2012048.
25. Gobena T, Berhane Y, Worku A. Low long-lasting insecticide nets (LLINs) use among household members for protection against mosquito bite in kersa, Eastern Ethiopia. BMC Public Health. 2012;12:914.

26. Afoakwah C, Nunoo J, Andoh FK. Effect of insecticide-treated bed net usage on under-five mortality in northern Ghana. Malar J. 2015;14:309.

27. Weber Cullen K, Baranowski T, Owens E, de Moor C, Rittenberry L, Olvera $\mathrm{N}$, et al. Ethnic differences in social correlates of diet. Health Educ Res. 2002; 17:7-18.

28. Slutsker L, Khoromana CO, Hightower AW, Macheso A, Wirima JJ, Breman JG, et al. Malaria infection in infancy in rural Malawi. Am J Trop Med Hyg. 1996;55:71-6.

29. Eisele TP, Keating J, Littrell M, Larsen D, Macintyre K. Assessment of insecticide-treated bednet use among children and pregnant women across 15 countries using standardized national surveys. Am J Trop Med Hyg. 2009;80:209-14.

30. Tariku A, Alemu K, Gizaw Z, Muchie KF, Derso T, Abebe SM, et al. Mothers' education and ANC visit improved exclusive breastfeeding in Dabat health and demographic surveillance system site, Northwest Ethiopia. PLoS One. 2017;12:e0179056.

31. Osamor PE, Grady C. Women's autonomy in health care decision-making in developing countries: a synthesis of the literature. Int J Womens Health. 2016;8:191-202

32. Tiruneh FN, Chuang K-Y, Chuang Y-C. Women's autonomy and maternal healthcare service utilization in Ethiopia. BMC Health Serv Res. 2017:17:718.

33. Nkoka O, Chuang T-W, Chuang K-Y, Chen Y-H. Factors associated with insecticide-treated net usage among women of childbearing age in Malawi: a multilevel analysis. Malar J. 2018;17:372.

34. Short SE, Mollborn S. Social determinants and health behaviors: conceptual frames and empirical advances. Curr Opin Psychol. 2015;5:78-84.

35. Katapa R. A comparison of female-and male-headed households in Tanzania and poverty implications. J Biosoc Sci. 2006;38:327-39.

36. Babalola S, Ricotta E, Awantang G, Lewicky N, Koenker H, Toso M. Correlates of intra-household ITN Use in Liberia: a multilevel analysis of household survey data. PLoS One. 2016;11:e0158331.

37. Sena LD, Deressa WA, Ali AA. Predictors of long-lasting insecticidetreated bed net ownership and utilization: evidence from communitybased cross-sectional comparative study, Southwest Ethiopia. Malar J. 2013;12:406.

38. Koenker H, Arnold F, Ba F, Cisse M, Diouf L, Eckert E, et al. Assessing whether universal coverage with insecticide-treated nets has been achieved: is the right indicator being used? Malar J. 2018:17:355.

39. Nketiah-Amponsah E. Mothers' demand for preventive health care for children aged under-five years: the case of utilization of insecticidetreated bednets in Ghana. J Sustain Develop. 2010;3:98.

40. Were V, Buff AM, Desai M, Kariuki S, Samuels A, Ter Kuile FO, et al. Socioeconomic health inequality in malaria indicators in rural western Kenya: evidence from a household malaria survey on burden and care-seeking behaviour. Malar J. 2018:17:166.

\footnotetext{
Ready to submit your research? Choose BMC and benefit from:

- fast, convenient online submission

- thorough peer review by experienced researchers in your field

- rapid publication on acceptance

- support for research data, including large and complex data types

- gold Open Access which fosters wider collaboration and increased citations

- maximum visibility for your research: over 100M website views per year
}

At BMC, research is always in progress.

Learn more biomedcentral.com/submissions 